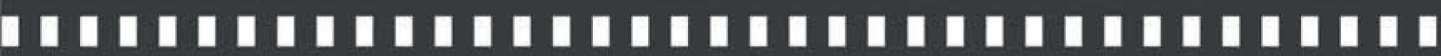

\author{
Resenha: As imagens mais fortes \\ que as experiências reais
}

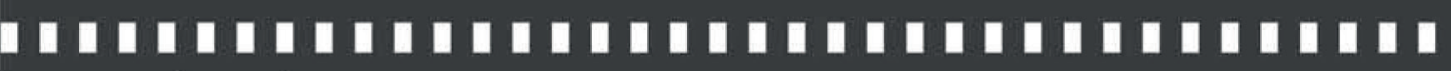

Marcio Fernandes 


\section{As imagens mais fortes que as experiências reais}

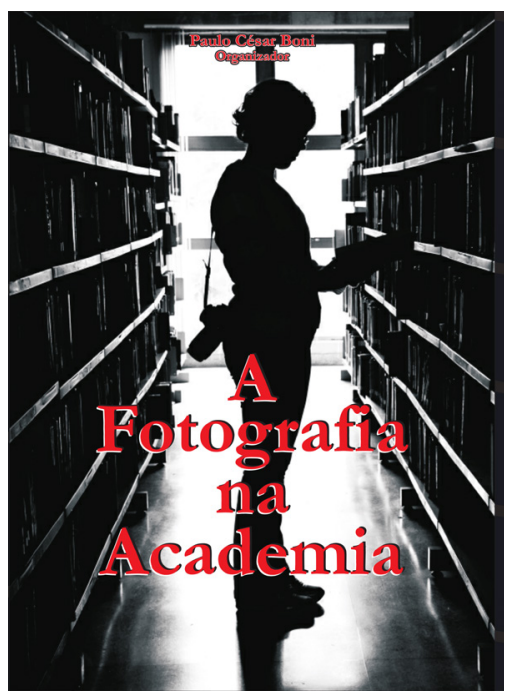

BONI, Paulo César (org). A Fotografia na Academia: de formadora de imaginários coletivos a fonte de pesquisas.

Londrina: Midiograf, 2015

Marcio Fernandes *

Se a visão de 1925 do Lázló Moholy-Nagy está correta, então nos deparamos agora diante de uma oportunidade ímpar: naquele tempo, o fotografo húngaro preconizou que o analfabeto do futuro seria aquele que não dominasse justamente o linguagem da Fotografia. E, decorrido quase um século das palavras desse

* Jornalista profissional e professor do Departamento de Comunicação Social (Decs) da Universidade Estadual do Centro-Oeste (Unicentro), Paraná. Doutor em Comunicação e Cultura pela UFRJ, com doutoramento-sanduíche pela Universidade de Lisboa (UL, Portugal).E-mail: marciofernandes@unicentro.br 
sábio que também se destacou em outros campos das Artes, tudo indica que ele estava (e está) certo. Dominar o campo da Imagem é um desafio que qualquer um de nós deveria fazer a si mesmo. E o recente livro "A Fotografia na Academia: de formadora de imaginários coletivos a fonte de pesquisa", de 2015, é uma bela ferramenta para que se dispõe a vencer tal desafio.

Logo de pronto, Paulo César Boni (organizador geral da obra) nos apresenta um panorama consistente do que foi, do que é e do que pode vir a ser a magia da Fotografia (p. 15):

Nascida no Positivismo - como uma suposta prova do real - , e como uma demanda da Revolução Industrial - que necessitava de um método de reprodução de imagens em série -, a Fotografia, ao longo de sua história, cumpriu diferentes funções sociais. Se no século XIX era objeto de ostentação da burguesia, que trocava seus carte de visites, atualmente permeia uma série de relações e comunicações virtuais entre indivíduos, via redes sociais, alocados em diferentes partes do mundo.

Bonitem propriedade sobre o que escreve. Tem conhecimento de causa, enquanto profissional da área e docente de referência no Brasil inteiro quando o tema é Fotografia. Ele prossegue (idem):

Nesse meio tempo, passou de mera ilustração de textos verbais a documento da História, e de acessório a objeto das Ciências Sociais, com o fortalecimento da Antropologia Visual como campo de pesquisa. Na Academia, a Fotografia, que antes era estudada apenas como formadora de imaginários, hoje é, e cada vez mais, aceita como fonte de pesquisa. Muitas pesquisas, em diversas áreas do conhecimento, foram propostas e desenvolvidas com base nas informações visuais contidas em fotografias, principalmente as de época. 
Bingo! É exatamente isso que comprovamos ao longo dos 11 capítulos da coletânea, distribuídos que estão em cerca de 250 páginas. Aqui nestas linhas, claro, seria possível apresentar cada uma das 11 divisões mas vale ressaltar dois dos textos. No primeiro deles, Fabiana Aline Alves (jornalista, doutoranda em História pela Unesp) nos faz recordar a mítica Copa do Mundo de 1970, cujas lembranças foram novamente retomadas com força no coletivo brasileiro no segundo semestre de 2016 pela morte física de Carlos Alberto Torres, o lateral direito daquele time e que está no epicentro de uma das mais poderosas cenas que o orgulho verde-amarelo tem para apresentar ao longo de seus mais de cinco séculos de existência: Torres, capitão do escrete nacional de 1970, braços ao alto, segurando a Taça Jules Rimet, a nossa Jules Rimet, como bem a Mídia ajudou a eternizar a partir daquele ano.

Fabiana discorre sobre o que chama de "estética realista do Fotojornalismo" que "dá suporte e corrobora com a mediação da Memória, apresentando e representando os acontecimentos cotidianos". Também com zelo e conhecimento de causa, Fabiana - cujo título do artigo é 'A taça do mundo é nossa': as relações entre futebol, política e fotojornalismo na conquista da Copa do Mundo Fifa de 1970 - discorre sobre as coberturas de tal evento realizadas pela revista semanal Veja (publicação incipiente naqueles tempos) e do jornal diário Folha de São Paulo (já antigo então mas sem o poder editorial que desfruta hoje) e suas relações com o momento ditatorial que vigorava no Brasil desde 1964.

Referenciando João Fernando Pelho Ferreira (2011), a autora pondera que "a imagem construída nos jornais e na TV, conforme o autor (Ferreira), centra-se apenas no aspecto mítico e heroico da vitória brasileira; já para os militares, o sucesso da seleção refletiria o período do milagre econômico no qual vivia a economia brasileira".

Ao longo de sua agradável prosa literária, Fabiana nos faz relembrar de algumas cenas que povoam o País há gerações: à página 43 está a reprodução de uma das capas daqueles dias da Folha SP, 
com a manchete Eles voltam amanhã com a taça. É a edição de 22 de junho de 1970, um dia depois da gloriosa partida no Estádio Azteca, na capital mexicana, em que a Seleção Canarinho (outro bordão com força até hoje na Imprensa) atropelou a Itália por 4 x 1 . A cena de Carlos Alberto com as mãos ao alto está estampada nesta primeira página da Folha. Pelé correndo para o abraço igualmente é destaque ali. Em outro espaço da mesma capa, o mesmo Pelé aparece desta vez sem camisa mas com um sombrero, um chapéu de design típico daquele país latino. Instantes para a posteridade, instantes para - vale reforçar - nosso orgulho nacional, o que me faz lembrar da sapiência de Gaston Bachelard, o filósofo francês para quem les images, qui sont des forces psychiques premières, sont plus fortes que les idées, plus fortes que les expérience réelles.

Nada mais acertado, Bachelard, nada mais acertado, já que, para milhões de brasileiros, as imagens que nos chegaram da competição perduram com força em nosso dia a dia mas, em especial, a cada quatro anos, quando a Nação renova suas expectativas e esperanças de que algum jogador canarinho consiga repetir o gesto de Carlos Alberto Torres.

Para além dos escritos de Fabiana, outro artigo que menciono é o que se chama Vale da Morte: a fotografia na consolidação da imagem negativa de Cubatão, de Sander Newton Mendes (especialista em Fotografia pela UEL) e Alexandre Torres Guimarães (doutor em Letras pela USP). Dentre aqueles que têm cerca de 40 anos certamente não é difícil recordar o noticiário dos anos 1980 que apresentava o município paulista de Cubatão como a cidade mais poluída do mundo, a partir de uma famigerada classificação dada pela Organização Mundial da Saúde, a OMS. Em Vale da Morte (alcunha dada pela Imprensa, do norte-americano The New York Times ao finado Jornal da Tarde, dentre ouros), os autores versam sobre "os impactos da poluição na construção da imagem negativa do município de Cubatão (SP) durante o processo de industrialização iniciado na década de 1950" (p. 94). Sander e Alexandre anotam que o assunto estava tão palpitante que não 
tardou para que outros da titãs Imprensa internacional despertassem interesse - em 1983, o prestigioso magazine americano Newsweek tratou do tema. No ano seguinte, foi a vez da alemã Der Spiegel. E estes são apenas dos casos.

Adiante, Sander e Alexandre mostram o outro lado - a recuperação ambiental forte e eficiente que Cubatão vivenciou nos anos seguintes, e o quão pouco tal recuperação acabou veiculada mundo afora, quando comparada com as reportagens e imagens negativas que haviam percorrido o planeta pouco antes. Eles pontuam e nos estimulam à reflexão:

Percebe-se, portanto, mais uma vez o poder de influência da comunicação de massa, capaz de padronizar um pensamento, um olhar acerca de algo, direcionando comportamentos e atitudes. Resta saber se, caso houvesse interesse maior das partes envolvidas e, por conseguinte, um apelo midiático em prol da vida, as imagens positivas e divulgadas regionalmente teriam repercussão a ponto de provocar uma mudança de opinião, transformando a 'poluída' Cubatão em uma cidade realmente recuperada ambiental e socialmente, com bons índices de qualidade de vida para seus habitantes.

Mas, uma vez pontuados estes dois belos exemplos de papers, é hora de nos voltarmos ao macro. A Fotografia na Academia... é também um apanhado consistente do que podemos chamar de Escola UEL de Estudos Fotográficos, um centro de pesquisa que, a partir de 1996 (com a criação do primeiro curso lato sensu do Brasil neste segmento das Ciências da Comunicação), começou a construir gradativamente sua trajetória, chegando sim à maioridade como um espaço de alto nível dentro e fora do País. Boni escreve(p. 16): "Desde sua criação, o curso da UEL prima pela formação teórica dos estudantes, ou seja, prioriza o pensar Fotografia, sem negligenciar o fazer Fotografia". 
A partir do contido na coletânea, descobrimos (ou rememoramos) que a revista Discursos Fotográficos data de 2005 e, por estes tempos, sendo lastreada em oito indexadores internacionais, do Scopus ao DOAJ e passando pelo Qualis e EBSCO. De maneira complementar, lemos que o grupo de pesquisa Comunicação e História já guarda 10 anos de atividades sequencialmente e que o pioneiro Mestrado em Comunicação focado em Comunicação Visual contabiliza 55 dissertações defendidas entre 2010 e 2014. Continua Boni:

Muitos estudantes do Mestrado em Comunicação vieram de outras instituições e para elas retornaram com o título de mestre. Com isso, pesquisadores da área de Fotografia estão se espalhando por instituições de Ensino Superior de diversos Estados e a UEL tem se consolidado como um celeiro da pesquisa e da formação de pesquisadores em Fotografia no Brasil.

E é exatamente este celeiro que se materializa no livro A Fotografia na Academia..., já que entrega aos leitores, como anota Boni (p. 19), os resultados de estudos desenvolvidos no âmbito do grupo, além de reflexões havidas no próprio Mestrado e em outros espaços, como teses de Doutorado em andamento. "Alguns trabalhos consolidam a Fotografia como formadora de imaginários coletivos, outros a utilizam como fonte de pesquisa", arremata Paulo César Boni.

Um dos componentes deste celeiro, Michel de Oliveira (aluno do referido Mestrado em 2016), recorre a Boris Kossoy (2005) para atestar a dimensão capital da Fotografia em nossas existências (p. 219):

Os homens colecionam esses inúmeros pedaços congelados do passado em forma de imagens para que possam recordar, a qualquer momento, trechos de sua 
trajetória ao longo da vida. Apreciando essas imagens, descongelam momentaneamente seus conteúdos e contam a si mesmos e aos mais próximos suas histórias de vida.

Palavras certeiras as de Kossoy, enfim, transcritas em uma obra que já merece seu lugar em nossas bibliotecas particulares ou públicas e que nasceu, foi gestada, tornou-se grande e se disseminou a partir de uma universidade, reiterando que os bancos escolares do Ensino Superior são sempre capazes de compreender os fenômenos mais impressionantes da trajetória humana - caso da Fotografia, essa criação que Henri Cartier-Bresson denominou de lição de amor e de ódio, de metralhadora e de diva do analista mas, sobretudo, de beijo cálido, que provoca uma paixão arrebatadora a cada vez que se apresenta diante de cada um de nós, enquanto uma poderosa força psíquica como bem disse Bachelard.

Incrível, não, a força de uma imagem? 